\title{
Evaluation of the electrocatalytic properties of Tungsten electrode towards hydrogen evolution reaction in acidic solutions
}

Ghada M. Abd El-Hafez ${ }^{\mathrm{a}}$, Nady H. Mahmoud ${ }^{\mathrm{a}}$, Alain Walcarius ${ }^{\mathrm{b}}$, Amany M. Fekry $^{\mathrm{c}}$

${ }^{a}$ Chemistry Department, Faculty of Science, Fayoum University, Fayoum, Egypt ${ }^{\mathrm{b}}$ CNRS-Université de Lorraine, LCPME UMR 7564, 405 Rue de Vandoeuvre, 54600 Villers-lès-Nancy, France

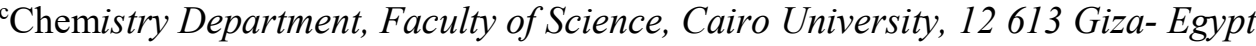

Corresponding author:

Name: Amany M. Fekry

Address: Chemistry Department, Faculty of Science, Cairo University, Giza-12613, Egypt Tel: 2020101545331

E-mail: amanym.fekry@gmail.com 


\section{Abstract}

Hydrogen has concerned interest universally as an environmentally nontoxic and renewable fuel. Electrocatalytic hydrogen evolution reaction (HER) is one of the utmost favorable methods for hydrogen creation on a vast scale; however, the high cost of Pt-based supplies, which demonstrate the highest activity for HER, forced investigators to look for cheaper electro-catalysts. Tungsten has been considered as an effective, active and low cost electrocatalyst for the hydrogen evolution reaction, mostly in alkaline media, and we have investigated here its behavior in acid electrolytes. HER has been studied utilizing linear polarization technique and electrochemical impedance spectroscopy (EIS). It happens on $\mathrm{W}$ at rather low overpotential (-0.32 V vs. NHE at $10 \mathrm{~mA} \mathrm{~cm}^{-2}$, in $\left.0.5 \mathrm{M} \mathrm{H}_{2} \mathrm{SO}_{4}\right)$, yet more cathodic than the widely used $\mathrm{Pt} / \mathrm{C}$ catalyst, but not so far from more sophisticated systems developed recently. The effect of acid concentration on the HER rate and the electrode stability was investigated. Cathodic transfer coefficient and exchange current density were calculated for the HER from Tafel curves obtained in $\mathrm{H}_{2} \mathrm{SO}_{4}$ solution at concentrations ranging from 0.1 to $3.0 \mathrm{M}$. EIS experiments were performed under both open circuit and/or cathodic polarization. It was found that the hydrogen evolution rate is relatively high under low overpotential, confirming that $\mathrm{W}$ is a possible applicant to substitute more expensive electrocatalysts usually used for the HER under acidic conditions. The process is economic and appropriate with no need for specific treatments, as supported by additional X-ray diffraction (XRD) and X-ray photoelectron spectroscopy (XPS) characterization of the tungsten electrode surface.

Keywords: Tungsten electrode; HER; Electrochemical activity; EIS. 


\section{Introduction}

Hydrogen production from water electrolysis is a significant work owing to its importance as an alternative to hydrogen energy manufacturing field [1-3]. "Hydrogen economy" is a possible substitute to energy systems using fossil derived fuels, either for its useful environmental influence or as a substitute for rapidly exhausting fossil fuels $[4,5]$. HER has been studied on different electrode materials with the goal to find more efficient conditions for $\mathrm{H}_{2}$ production. The active materials for HER should be of large active surface area, highly intrinsic electrocatalytic activity, stable and of low cost $[4,6]$.

It is well recognized that noble metals like platinum, $\mathrm{Pt}$, and palladium, $\mathrm{Pd}$ (especially $\mathrm{Pt} / \mathrm{C}$ and $\mathrm{Pd} / \mathrm{C}$ ) have high efficient catalytic performance for the $\mathrm{H}_{2}$ production, good chemical stability, large surface area with low overpotential in acid media [7]. However, their high price reduces their utilization for industrial applications $[8,9]$. Therefore, much effort has been exhausted to find costeffective, earth-abundant metal based compounds as a highly efficient HER catalyst [10].

Recently, non-precious metals like Ni [11], Co [12], W [13] or Mo [14], and/or non-noble metal-based materials, such as transition metal sulfides, nitrides, phosphides, carbides and carbonaceous materials, which have been stated as efficient HER catalysts replacing noble metal catalysts [15-17]. This is not only due to their chemical stability, but also because of their low cost and low HER overpotential $[13,14]$. In the tungsten family, more sophisticated W-based systems have been also reported for HER, including for instance tungsten carbide, tungsten oxide, tungsten sulfide or phosphide, tungsten-based alloys, or their multicomponent composites [18-30]. Note that tungsten oxide can be also used as 
electrocatalyst for oxygen reduction [28]. Finally, one noticed also recent efforts directed towards the photocatalytic hydrogen generation using tungsten-based (nano) materials [31-39].

W was utilized successfully to produce $\mathrm{H}_{2}$ from $\mathrm{KOH}$ solutions at a reasonable rate and for a relatively long time $[13,40]$. This is due to its superior electronic conductivity [41] that makes it significant candidate for electrocatalytic HER. The disadvantages of $\mathrm{H}_{2} \mathrm{O}$ alkaline electrolysis processes are mainly related to their low efficiency and high energy consumption [42-43].

Hence, W metal is inspected as a catalyst for the HER in this work in acid solution which provides a potential alternative to this issue. It is aimed to utilize it as an effective cathode for hydrogen evolution at low hydrogen overpotential in $\mathrm{H}_{2} \mathrm{SO}_{4}$ solution. This suggestion was done especially on tungsten owing to its low cost, superior electronic properties and easily available. The electrochemical and catalytic characteristics of this electrode were investigated here on the basis of potentiometry and linear scan voltammetry (LSV) measurements as well as electrochemical impedance spectroscopy (EIS). Also, composition and morphological or structural properties have been included on the basis of SEM, EDX, XRD and XPS measurements.

\section{Experimental}

The $\mathrm{W}$ rod (Sigma Aldrich of cross-section area of $0.2 \mathrm{~cm}^{2}$ ) was embedded in epoxy resin and then polished using successive grades of emery papers down to 2000 grit then washed with triple distilled water and transferred quickly to the electrolytic cell. The W working electrode was held using a PTFE holder. Its electrochemical response was evaluated in $\mathrm{H}_{2} \mathrm{SO}_{4}$ medium (Sigma Aldrich) using 
the Voltalab PGZ 100 workstation, most often with a three-electrode cell as stated previously in Badawy et al. [13] work. Triple distilled water was used.

The open circuit potential, OCP, was recorded for $1 \mathrm{~h}$ and all potential values are referred to the saturated calomel reference electrode $(\mathrm{SCE},+0.241 \mathrm{~V}$ vs. NHE). All experiments were conducted at room temperature $\left(25 \pm 1{ }^{\circ} \mathrm{C}\right)$. Linear sweep voltammetry was performed at a scan rate of $5 \mathrm{mV} \mathrm{s}^{-1}$. EIS tests were performed at OCP potential and at different overpotentials in the $\mathrm{H}_{2}$ evolution region with a $10 \mathrm{mV}$ amplitude at frequency ranging from $1 \mathrm{mHz}$ to $100 \mathrm{kHz}$. The polarization and EIS tests were repeated three times. Pt electrode was used for comparison purposes.

Surface morphology and characterization was achieved utilizing the scanning electron microscope (SEM) (Model Quanta 250 Field Emission Gun) coupled with energy dispersive x-ray (EDX) Unit (FEI Company, Netherlands). XPS was collected on K-ALPHA (Themo Fisher Scientific, USA) with monochromatic Xray $\mathrm{Al} \mathrm{K}$-alpha radiation -10 to $1350 \mathrm{eV}$ spt size 400 micro $\mathrm{m}$ at pressure $10-9$ mbar with full spectrum pass energy $200 \mathrm{eV}$ and at narrow spectrum $50 \mathrm{eV}$. XRD instrument was ... Surface roughness was measured using the Nanosurf C3000 atomic force microscopy (AFM) apparatus.

\section{Results and discussion}

\subsection{Preliminary characterization of $W$ electrodes}

The polished $\mathrm{W}$ rod electrode exhibited a flat surface (its roughness has been estimated from AFM imaging at about $45 \mathrm{~nm}$ ), yet with noticeable polishing striations (see SEM micrograph on Fig. 1A), without any other detectable elements (as pointed out from EDX analysis, see Fig. 1B). XPS examination of its surface state (see the narrow scan corresponding to the $\mathrm{W}$ region on Fig. 1C) 
reveals the presence of two main contributions of $\mathrm{W}(4 f)$ at binding energies of respectively 31.3 and $33.5 \mathrm{eV}$, which are characteristics of metallic $\mathrm{W}^{0}$, and two small peaks located at 35.6 and $37.8 \mathrm{eV}$ generally attributed to tungsten oxidized to its hexavalent state $\left(\mathrm{WO}_{3}\right)$ [44-46]. The small amount of oxidized tungsten was even less after contacting a $0.5 \mathrm{M} \mathrm{H}_{2} \mathrm{SO}_{4}$ solution (i.e., the medium in which most of electrochemical measurements will be performed, as described below), which should be due to some wet etching of $\mathrm{WO}_{3}$ likely to occur in very acidic medium $[46,47]$. The residual $\mathrm{WO}_{3}$ signature might be also due to the fact that the $\mathrm{W}$ sample was briefly exposed to air prior to XPS analysis, and might therefore not reflect exactly the surface state of the electrode in the electrolyte medium (as otherwise reported for air-sensitive materials [48]).

Both crude $\mathrm{W}$ electrode and $\mathrm{W}$ electrode treated with $0.5 \mathrm{M} \mathrm{H}_{2} \mathrm{SO}_{4}$ have been characterized by XRD. The results (Fig. 2) indicate the expected body-centered cubic phase characteristic of W [49]. The same diffraction lines were observed for both crude and treated electrodes, with the typical reflections shown as (002), (110), (200), (211) and (220), respectively located at $2 \theta$ values of $29^{\circ}, 40^{\circ}, 58^{\circ}, 73^{\circ}$ and $87^{\circ}$. No noticeable difference can be seen after $\mathrm{W}$ treatment in $0.5 \mathrm{M} \mathrm{H}_{2} \mathrm{SO}_{4}$, and no crystalline $\mathrm{WO}_{3}$ can be detected, suggesting that the small amount of oxide evidenced from XPS is either too low to be detected by XRD or amorphous.

\subsection{Open circuit potential}

The open-circuit potentials, EOCP, of W (Fig. 3a) were monitored over $1 \mathrm{~h}$ in aerated $\mathrm{H}_{2} \mathrm{SO}_{4}$ solution of various concentrations. EOCP was reached in $\sim 30$ minutes at all acid concentrations, It shifted positively at first few minutes and then a gradual increase of potential with time until a steady state value is obtained (the relatively steady values are in the range of 0 to $0.50 \mathrm{mV}$ ). This means a 
passivation and healing of $\mathrm{W}$ in aqueous media even with using a high acid concentration. By increasing the $\mathrm{H}_{2} \mathrm{SO}_{4}$ concentration from $0.1-0.5 \mathrm{M}$, there is no appreciable change in the steady state potential, $E_{\mathrm{ss}}$. At higher concentration of $\mathrm{H}_{2} \mathrm{SO}_{4}(>0.5 \mathrm{M})$, the EOCP of the $\mathrm{W}$ electrode shifts toward more positive values indicating healing ( $c f$. Fig. 3a). For comparison, the EocP for Pt in $0.5 \mathrm{M} \mathrm{H}_{2} \mathrm{SO}_{4}$ solution was also outlined and the results of both $\mathrm{Pt}$ and $\mathrm{W}$ are set in Fig. 3b. The results indicate much more negative steady-state potential for $\mathrm{W}$ compared to $\mathrm{Pt}$.

\subsection{Electrocatalytic evolution of hydrogen on Welectrode}

The HER electrocatalytic activity for $\mathrm{W}$ electrode was estimated by the cathodic current-potential curves in different $\mathrm{H}_{2} \mathrm{SO}_{4}$ acid concentrations (Fig. 4a) and examined in comparison with commercial Pt electrode. The increase of $\mathrm{H}_{2} \mathrm{SO}_{4}$ concentration from 0.1 to $3.0 \mathrm{M}$ resulted in different current densities related to the HER increasing from 95 to $592 \mathrm{~mA} \mathrm{~cm}^{-2}$ at $-1.0 \mathrm{~V}$ and from 182 to $1470 \mathrm{~mA}$ $\mathrm{cm}^{-2}$ at $-1.5 \mathrm{~V}$. This means that the $\mathrm{H}_{2}$ production can be controlled by the electrolyte concentration. Fig. $4 \mathrm{~b}$ illustrates the hydrogen evolution behavior of W, in comparison to Pt in $0.5 \mathrm{M} \mathrm{H}_{2} \mathrm{SO}_{4}$ solution, where the Pt catalyst exhibits the highest HER catalytic activity in the same solution, larger than that recorded on W electrode. These values are estimated from Fig. 4b, after enlargement of the current scale at $10 \mathrm{~mA} \mathrm{~cm}^{-2}$ are $-0.32 \mathrm{~V}$ and $-0.08 \mathrm{~V}$ vs. NHE (in $0.5 \mathrm{M} \mathrm{H}_{2} \mathrm{SO}_{4}$ ), respectively, for $\mathrm{W}$ and $\mathrm{Pt}$ electrodes. The steady state potentials of $\mathrm{Pt}$ and $\mathrm{W}$ are 485 and $-2 \mathrm{mV}$, respectively, (cf. Fig. $3 \mathrm{~b}$ ). The potential at which $\mathrm{H}_{2}$ starts to evolve in the same solution on the two different electrodes is -310 and $-596 \mathrm{mV}$ for Pt and W, respectively (cf. Fig. 4b). Thus, the potential jump for HER on W amounts to $-594 \mathrm{mV}$ whereas that on $\mathrm{Pt}$ is $-795 \mathrm{mV}$. So, $\mathrm{W}$ is an effective catalyst for $\mathrm{H}_{2}$ production in $\mathrm{H}_{2} \mathrm{SO}_{4}$ solutions. To compare between $\mathrm{W}$ and $\mathrm{Pt}$ according to 
HER rate using similar polarization circumstances, the current density on $\mathrm{W}$ at $1.0 \mathrm{~V}$ from the steady-state potential amounts to $210 \mathrm{~mA} \mathrm{~cm}^{-2}$, i.e. only twice as less than on Pt $\left(410 \mathrm{~mA} \mathrm{~cm}^{-2}\right)$. The presented data were extracted from Fig. $4 \mathrm{~b}$ at a concentration of $0.5 \mathrm{M} \mathrm{H}_{2} \mathrm{SO}_{4}$ only. It was found that the hydrogen evolution rate is relatively high under low overpotential $(-1 \mathrm{~V})$. This confirms well confirming that $\mathrm{W}$ is a possible applicant as low cost electrocatalyst for the HER under acidic conditions. At higher concentration the rate of hydrogen evolution on W will be higher ( $c f$. Fig. 4a). It means that even for practical applications when one needs to work in higher acid concentrations, $\mathrm{W}$ can act effectively as a catalyst for the HER in acidic electrolytes, yet achieving $50 \%$ of the performance in terms of current density when compared to Pt electrode. A more detailed comparison to other electrocatalysts investigated in the past few years (Table 1) shows that the overpotential values for $\mathrm{W}$ from the present study remains quite high, but not that much in comparison to other systems [50-87] that are often more sophisticated in terms of composition, (nano)structure or preparation methods, than a simple $\mathrm{W}$ rod as used here.

Fig. 5 presents the polarization scans of the HER on $\mathrm{W}$ electrode at different $\mathrm{H}_{2} \mathrm{SO}_{4}$ concentrations fitted well with the Tafel equation [13]. The kinetic parameters were derived by the extrapolation method and are summarized in Table 2. The slope of the cathodic Tafel line, $b$, is given by: $b=2.3 \mathrm{RT} /(1-\alpha) \mathrm{F}$, where it is inversely proportional to the cathodic transfer coefficient, $(1-\alpha)$. The exchange current density, $i_{\mathrm{o}}$, is obtained from the intersection of Tafel lines. Generally, to convert $\mathrm{H}^{+}$protons to $\mathrm{H}_{2}$ in acidic electrolytes, three elementary reaction steps are involved $[88,89]$, as follow.

A primary discharge step (Volmer reaction): 
$\mathrm{M}+\mathrm{H}_{3} \mathrm{O}^{+}+\mathrm{e}^{-} \rightarrow \mathrm{M}-\mathrm{H}_{\mathrm{ads}}+\mathrm{H}_{2} \mathrm{O}\left(b=\frac{2.3 R T}{\alpha F} \approx 120 \mathrm{mV}\right)$

An electrochemical-desorption step (Heyrowsky reaction):

$\mathrm{M}-\mathrm{H}_{\mathrm{ads}}+\mathrm{H}_{3} \mathrm{O}^{+}+\mathrm{e}^{-} \rightarrow \mathrm{H}_{2} \uparrow+\mathrm{M}+\mathrm{H}_{2} \mathrm{O}\left(b=\frac{2.3 R T}{(1+\alpha) F} \approx 40 \mathrm{mV}\right)$

and A recombination step (Tafel reaction):

$2 \mathrm{M}-\mathrm{H}_{\mathrm{ads}} \rightarrow \mathrm{H}_{2} \uparrow+2 \mathrm{M}\left(b=\frac{2.3 R T}{2 F} \approx 30 \mathrm{mV}\right)$

Molecular $\mathrm{H}_{2}$ can be produced when reaction (1) is combined with reaction (2), or reaction (3). For materials that are good catalysts toward $\mathrm{H}_{2}$ production (HER), the Tafel reaction is the rate-determining step $(r d s)$ at low overpotentials, while at higher overpotentials, the Heyrovsky reaction becomes the $r d s$ [90]. The right reaction mechanism can't be simply known. As example, the Tafel slope for the HER on the $\operatorname{Pt}(110)$ was $28 \mathrm{mV} / \mathrm{dec}$, indicating the reaction pathway to the TafelVolmer mechanism [91]. By knowing the evaluated values, we can assume that the route for HER on $\mathrm{W}\left(b=25 \mathrm{mV} \mathrm{dec}^{-1} c f\right.$. Table 1) should follow VolmerTafel steps, where Tafel reaction is the rds. It is also evaluated that the exchange current density increases with the $\mathrm{H}_{2} \mathrm{SO}_{4}$ concentration. To know the actual meaning of the Tafel slope, the right value of the transfer coefficient $\alpha$ should be known. The transfer coefficient for the HER is given to be between 0 and 1 [92]. The cathodic transfer coefficient decrease by a small value with increasing the $\mathrm{H}^{+}$ concentrations with an increase of exchange current density $i_{0}$, leading to an overall effect of HER enhancement [93]. Comparison to other HER catalysts indicates that Tafel slope achieved here with $\mathrm{W}$ electrode is amongst the smallest values reported to date for other electrode materials (Table 1). 


\subsection{EIS investigations of $W$ electrode.}

Metallic catalysts are likely to be corroded, inducing a decrease in its performance when utilized in industrial applications (activity and lifetime drops). Hence, EIS is an appropriate technique to characterize such behavior [94-99]. The Bode plots of W electrode after $1 \mathrm{~h}$ immersion in an aerated solution of different $\mathrm{H}_{2} \mathrm{SO}_{4}$ concentrations were given in Fig. 6 . They show a broad two time constants with a maximum phase angle of $\sim 90^{\circ}$ demonstrating that the corrosion reaction is mostly controlled by a charge transfer process. The phase diagram shape or phase angle maximum does not vary with the $\mathrm{H}_{2} \mathrm{SO}_{4}$ concentration $[99,100]$ ensuring the same reaction mechanism (Fig. 6). The data are fitted well utilizing an equivalent circuit model constituting a solution resistance, $R_{\mathrm{S}}$ in series with a two parallel combinations consisting of a resistor representing the charge transfer resistance of outer and inner layer, $R_{1}, R_{2}$, respectively, and a constant phase element (CPE), $C P E_{1}, \mathrm{CPE}_{2}$, respectively, representing the double layer capacitance of the outer and inner layer ( $c f$. Fig. 6 (inset)). The CPE is introduced to account for the nonideality of the surface [101-103] including $\alpha$ as an empirical parameter $(0 \leq \alpha \leq 1)$ and $f$ as the frequency in $\mathrm{Hz}[104,105]$. The experimental results were fitted to the circuit inset in Fig. 6 and the calculated parameters are given in Table 3. The total charge transfer resistance $\left(\mathrm{R}_{\mathrm{T}}\right)$ (Table 3 ) was found to be increased with increasing the concentration of $\mathrm{H}_{2} \mathrm{SO}_{4}$ indicating a higher stability of $\mathrm{W}$ electrode at higher acidic solutions due to the formation of less soluble heteropolytungstates [100].

Fig. 7 presents the Bode and Nyquist plots of the $\mathrm{W}$ catalyst in $\mathrm{H}_{2} \mathrm{SO}_{4}$ solutions at various concentrations, as polarized catholically at a potential of -750 $\mathrm{mV}$, where the HER is taking place at a measurable rate. Generally, the total 
impedance, $Z$, under cathodic polarization, is lower (cf. Fig. 7a) owing to the activation of the $\mathrm{W}$ surface due to the HER. The $\theta_{\max }$ value shifts toward lower values and the impedance, $Z$, value decreases in more concentrated $\mathrm{H}_{2} \mathrm{SO}_{4}$ solutions, indicating an increase in the rate of $\mathrm{H}_{2}$ generation (HER). There is no broadening of phase diagram meaning that the rate of hydrogen production is appreciably high. Only one depressed semicircle was observed in Nyquist plot for W catalyst at all $\mathrm{H}_{2} \mathrm{SO}_{4}$ concentrations ( $c f$. Fig. $7 \mathrm{~b}$ ), which becomes smaller in more concentrated $\mathrm{H}_{2} \mathrm{SO}_{4}$ due to the fact that the adsorption process is facilitated and the charge transfer process controls the mechanism as the concentration increases. The data can be adjusted utilizing the simple Randles model (Fig. 7b) and fitting values [106-110] are presented in Table 4. The charge-transfer resistance decreases as the acid concentrations increases. This confirms well the increase in the current density, i.e. the increase in HER rate. Fig. 8 presents the Bode and Nyquist plots performed after different intervals of electrode immersion in $0.5 \mathrm{M} \mathrm{H}_{2} \mathrm{SO}_{4}$ at a cathodic potential of $-750 \mathrm{mV}$. $\mathrm{R}_{\mathrm{T}}$ increases due to a progressive adsorption of $\mathrm{H}^{+}$on the electrode surface [7] as given in Table 5. The resistance of the adsorbed layer increases with increasing immersion time indicating increased adsorption of hydrogen on the electrode surface [111].

\section{Conclusions}

This work has investigated the electrocatalytic properties of tungsten electrode in $0.5 \mathrm{M} \mathrm{H}_{2} \mathrm{SO}_{4}$ for hydrogen evolution reactions. Polarization and impedance results have shown that the hydrogen production occurs at a reasonable overpotential on W compared to other HER catalysts, yet more cathodic than the most efficient used to date (i.e., Pt/C or novel nanostructured catalysts), however, from cost 
comparison $\mathrm{W}$ is better economically. Tungsten catalyst exhibited high HER activity with an overpotential of $-0.32 \mathrm{~V}$ vs. NHE (at $10 \mathrm{~mA} \mathrm{~cm}$, in $0.5 \mathrm{M}$ $\mathrm{H}_{2} \mathrm{SO}_{4}$ ), large cathodic current, and a Tafel slope as small as $25 \mathrm{mV} /$ decade, which makes them perspective for application in acidic electrolyzers for hydrogen production. 


\section{References}

1. Mizuno T, Enyo M, Sorption of hydrogen on and in hydrogen absorbing metals in electrochemical environment. In: Modern aspects of electrochemistry, New York: Plenum 1996;35:415.

2. Viswanathan B. In: Viswanathan B, editor. Catalysis. New Delhi, India: Narosa Publishing House;2002:390.

3. Losiewicz B, Budniok A, Rowinski E, Lagiewka E, Lasia A. The structure, morphology and electrochemical impedance study of the hydrogen evolution reaction on the modified nickel electrodes. Int J Hydrogen Energy 2004;29:145-157.

4. Crabtree GW, Dresselhaus MS, Buchanan MV. The hydrogen economy. Phys Today 2004;57:39-45.

5. Tseng P, Lee J, Friley P. A hydrogen economy: opportunities and challenges. Energy 2005;30:2703-2720.

6. Navarro-Flores E, Omanovic S. Hydrogen evolution on nickel incorporated in three-dimensional conducting polymer layers. Mol Catal A: Chem 2005;242:182-194.

7. Sarkar S, Peter S. An overview on Pd-based electrocatalysts for the hydrogen evolution reaction, Inorg. Chem. Front., 2018;5:2060-2080.

8. Huang H, Zhang X, Zhang Y, Huang B, Cai J, Lin S, Facile synthesis of laminated porous WS2/C composite and its electrocatalysis for oxygen reduction reaction. Int J Hydrogen Energy 2018;43:8290-8297.

9. Grigoriev S, Porembsky V, Fateev V. Pure hydrogen production by PEM electrolysis for hydrogen energy. Int J Hydrogen Energy 2006;31:171-175. 
10. Imran M, Yousaf A, Zaidi S, Fernandez C. Tungsten-molybdenum oxide nanowires/reduced graphene oxide nanocomposite with enhanced and durable performance for electrocatalytic hydrogen evolution reaction, Int $\mathrm{J}$ Hydrogen Energy 2017;42;8130-8138.

11. Popczun EJ, McKone JR, Read CG, Biacchi AJ, Wiltrout AM, Lewis NS, Schaak RE. Nanostructured nickel phosphide as an electrocatalyst for the hydrogen evolution reaction. J Am Chem Soc 2013;135:9267-9270.

12. Zhong H, Campos-Roldan CA, Zhao Y, Zhang S, Feng Y, Alonso-Vante N. Recent advances of cobalt-based electrocatalysts for oxygen electrode reactions and hydrogen evolution reaction. Catalysts 2018;8:559.

13. Badawy WA, Abd El-Hafez GM, Nady H. Electrochemical performance of tungsten electrode as cathode for hydrogen evolution in alkaline solutions. Int J Hydrogen Energy 2015;40:6276-6282.

14. Badawy WA, Feky HE, Helal NH, Mohammed HH. Hydrogen production on molybdenum in $\mathrm{H}_{2} \mathrm{SO}_{4}$ solutions. J Power Sources 2014;271:480-488.

15. Shi, Y.; Zhang, B. Recent advances in transition metal phosphide nanomaterials: synthesis and applications in hydrogen evolution reaction. Chem Soc Rev 2016;45:1529-1541.

16. Liu, Y.; Li, Y.; Kang, H.; Jin, T.; Jiao, L. Design, synthesis, and energyrelated applications of metal sulfides, Mater Horizons 2016;3:402-421.

17. Li, X.; Hao, X.; Abudula, A.; Guan, G. Nanostructured catalysts for electrochemical water splitting: current state and prospects. J Mater Chem A 2016;4:11973-12000. 
18. Zhang Y, Bilan HK, Podlaha E. Enhancing the hydrogen evolution reaction with Ni-W-TiO 2 composites Electrochem Commun 2018;96:108-112.

19. Nayak AK, Verma M, Sohn Y, Deshpande PA, Pradhan D. Highly Active Tungsten Oxide Nanoplate Electrocatalysts for the Hydrogen Evolution Reaction in Acidic and Near Neutral Electrolytes. ACS Omega 2017;2:7039-7047.

20. Li YH, Liu PF, Pan LF, Wang HF, Yang ZZ, Zheng LR, Hu P, Zhao HJ, Gu L, Yang HG. Local atomic structure modulations activate metal oxide as electrocatalyst for hydrogen evolution in acidic water. Nature Commun $2015 ; 6: 8064$.

21. Fei H, Yang Y, Fan X, Wang G, Ruan G, Tour JM. Tungsten-based porous thin-films for electrocatalytic hydrogen generation. J Mater Chem A 2015;3:5798-5804.

22. Park I, Kim W, Kim E, Bae S, Kim J, Shin H. Electrochemical Reactivity of Chemically Roughened Tungsten Electrodes. Asian J Chem 2013;25:70377040.

23. Struck B, Neumeister H., Naoumidis A., Tungsten carbide cathodes for hydrogen production in acidic electrolytes, Int $\mathrm{J}$ Hydrogen Energy $1986 ; 11: 541-548$.

24. Zóltovski P., Hydrogen evolution reaction on smooth tungsten carbide electrodes, Electrochim Acta 1980;25:1547-1554.

25. Wondimu T., Chen G., Kabtamu D., Chen H., Bayeh A., Huang H., Wang C., Highly efficient and durable phosphine reduced iron-doped tungsten oxide/reduced graphene oxide nanocomposites for the hydrogen evolution reaction, Int J Hydrogen Energy 2018;43:6481-6490. 
26. Abbas S., Wu J., Huang Y., Babu D., Anandhababu G., Ghausi M., Wu M., Wang Y., Novel strongly coupled tungsten-carbon-nitrogen complex for efficient hydrogen evolution reaction, Int J Hydrogen Energy 2018;43:1623.

27. Han N., Yang K., Lu Z., Li Y., Xu W., Gao T., Cai Z., Zhang Y., Batista V., Liu W., Sun X., Nitrogen-doped tungsten carbide nanoarray as an efficient bifunctional electrocatalyst for water splitting in acid, Nature Commun 2018;9:924.

28. Nsanzimana J., Peng Y., Miao M., Reddu V., Zhang W., Wang H., Xia B., Wang X., An Earth-Abundant Tungsten-Nickel Alloy Electrocatalyst for Superior Hydrogen Evolution, ACS Appl Nano Mater 2018;1:1228-1235.

29. McEnaney J., Chance Crompton J., Callejas J., Popczun E., Read C., Lewis N., Schaak R., Electrocatalytic hydrogen evolution using amorphous tungsten phosphide nanoparticles, Chem Commun 2014;50:11026-11028.

30. Wu L., Pu Z., Tu Z., Amiinu I., Liu S., Wang P., Mu S., Integrated design and construction of WP/W nanorod array electrodes toward efficient hydrogen evolution reaction, Chem Eng J 2017;327:705-712.

31. Liu Y., Shrestha S., Mustain W, Synthesis of Nanosize Tungsten Oxide and Its Evaluation as an Electrocatalyst Support for Oxygen Reduction in Acid Media, ACS Catal 2012;2:456-463.

32. Tahir M., Nabi G, Rafique M, Khalid N. Nanostructured-based $\mathrm{WO}_{3}$ photocatalysts: recent development, activity enhancement, perspectives and applications for wastewater treatment. Int J Environ Sci Technol 2017;14:2519-2542. 
33. Tahir M, Sagir M, Shahzad K. Removal of acetylsalicylate and methyltheobromine from aqueous environment using nano-photocatalyst $\mathrm{WO}_{3}$ $\mathrm{TiO}_{2} @ \mathrm{~g}-\mathrm{C}_{3} \mathrm{~N}_{4}$ composite, J Hazardous Mater 2019;363:205-213.

34. Tahir M, Sagir M. Carbon nanodots and rare metals $(\mathrm{RM}=\mathrm{La}, \mathrm{Gd}, \mathrm{Er})$ doped tungsten oxide nanostructures for photocatalytic dyes degradation and hydrogen production, Sep Purif Technol 2019;209:94-102.

35. Tahir M. Construction of $\mathrm{MoS}_{2} / \mathrm{CND}-\mathrm{WO}_{3}$ Ternary Composite for Photocatalytic Hydrogen Evolution, J Inorg Organomet Polym Mater 2018;28:2160-2168.

36. Tahir M, Nabi G, Khalid N. Enhanced photocatalytic performance of visible-light active graphene- $\mathrm{WO}_{3}$ nanostructures for hydrogen production, Mater Sci Semicond Process 2018;84:36-41.

37. Tahir M, Nabi G, T.Iqbal T, Sagir M, Rafique M. Role of $\mathrm{MoSe}_{2}$ on nanostructures $\mathrm{WO}_{3}-\mathrm{CNT}$ performance for photocatalytic hydrogen evolution. Ceram Int 2018;44:6686-6690.

38. Tahir M, Nabi G, Khalid N, Rafique $\mathrm{M}$. Role of europium on $\mathrm{WO}_{3}$ performance under visible-light for photocatalytic activity. Ceram Int 2018;44:5705-5709.

39. Tahir M, Asiri A, Nabi G, Rafique M, Sagir M. Fabrication of heterogeneous photocatalysts for insight role of carbon nanofibre in hierarchical $\mathrm{WO}_{3} / \mathrm{MoSe}_{2}$ composite for enhanced photocatalytic hydrogen generation. Ceram Int 2019;45:5547-5552.

40. Borresen B, Hagen G, Tunold R. Hydrogen evolution on $\mathrm{Ru}_{x} \mathrm{Ti}_{1-x} \mathrm{O}_{2}$ in 0.5 $\mathrm{M} \mathrm{H}_{2} \mathrm{SO}_{4}$. Electrochim Acta 2000;47:1819-1827. 
41. Liu C, Zhou J, Xiao Y, Yang L, Yang D, Zhou D, Structural and electrochemical studies of tungsten carbide/carbon composites for hydrogen evolution, Int J Hydrogen Energy 2017;42:29781-29790.

42. Tuvic T, Pasti I, Mentus SV, A rotating tungsten disc electrode in concentrated strong alkaline solutions: an electroanalytical aspect, J Electroanal Chem 2011;654:102-107.

43. Kelly EJ, Bronstein HR. Kinetics and Mechanism of the Hydrogen Evolution Reaction on Titanium in Acidic Media. J Electrochem Soc $1984 ; 131: 2232-2238$

44. Tamboli D, Seal S, Desai V, Maury A, Tamboli D, Seal S, Desai V, Maury A. Studies on passivation behavior of tungsten in application to chemical mechanical polishing. J Vacuum Sci Technol 1999;17:1168-1173.

45. Kamiura Y., Umezawa K, Teraoka Y, Yoshigoe A. Characterization of polycrystalline tungsten surfaces irradiated with nitrogen ions by X-ray photoelectron spectroscopy. Mater Trans 2016;57:1609-1614.

46. Votta A., Pipia F, Borsari S, Ravizza E, Elbaz A, Alessandri M, Bellandi E, Bresolin C. Influence of Wet Cleaning on Tungsten Deposited with Different Techniques, Solid State Phenom 2009, 145-146, 197-200.

47. Reichman B, Bard AJ. The Electrochromic Process at $\mathrm{WO}_{3}$ Electrodes Prepared by Vacuum Evaporation and Anodic Oxidation of W. J Electrochem Soc 1979;126:583-591.

48. Bogdanoff P, Harbauer K, Plate P, Höhn C, Rappich J, Wang B, Han X, van de Krol R, Fiechter S. Structural Transformation Identification of Sputtered Amorphous MoSx as an Efficient Hydrogen-Evolving Catalyst during Electrochemical Activation. ACS Catal 2019;9:2368-2380. 
49. Majumdar S, Kishor J, Paul B, Kain V, Dey GK. Demonstration of Production of Tungsten Metal Powder and its Consolidation into Shapes. BARC Newsletter 2016, pp. 30-33.

50. Chen, Z.; Cummins, D.; Reinecke, B. N.; Clark, E.; Sunkara, M. K.; Jaramillo, T. F. Core-shell $\mathrm{MoO}_{3}-\mathrm{MoS}_{2}$ Nanowires for Hydrogen Evolution: A Functional Design for Electrocatalytic Materials. Nano Lett $2011 ; 11: 4168-4175$.

51. Wang, T. Y.; Liu, L.; Zhu, Z. W.; Papakonstantinou, P.; Hu, J. B.; Li, M. Enhanced Electrocatalytic Activity for Hydrogen Evolution Reaction from Self-Assembled Monodispersed Molybdenum Sulfide Nanoparticles on an Au Electrode. Energy Environ Sci 2013;6: 625-633.

52. Xie, J.; Zhang, H.; Li, S.; Wang, R.; Sun, X.; Zhou, M.; Zhou, J.; Lou, X. W.; Xie, Y. Defect-Rich $\mathrm{MoS}_{2}$ Ultrathin Nanosheets with Additional Active Edge Sites for Enhanced Electrocatalytic Hydrogen Evolution. Adv Mater $2013 ; 25: 5807-5813$.

53. Popczun, E. J.; McKone, J. R.; Read, C. G.; Biacchi, A. J.; Wiltrout, A. M.; Lewis, N. S.; Schaak, R. E. Nanostructured Nickel Phosphide as an Electrocatalyst for the Hydrogen Evolution Reaction. J Am Chem Soc 2013;135:9267-9270.

54. Kong, D. S.; Cha, J. J.; Wang, H. T.; Lee, H. R.; Cui, Y. First-Row Transition Metal Dichalcogenide Catalysts for Hydrogen Evolution Reaction. Energy Environ Sci 2013;6:3553-3558.

55. Liu, Q.; Tian, J. Q.; Cui, W.; Jiang, P.; Cheng, N. Y.; Asiri, A. M.; Sun, X. P. Carbon Nanotubes Decorated with CoP Nanocrystals: A Highly Active 
Non-Noble-Metal Nanohybrid Electrocatalyst for Hydrogen Evolution. Angew Chem Int Ed 2014;53:6710-6714.

56. Fu, Q.; Yang, L.; Wang, W.; Han, A.; Huang, J.; Du, P.; Fan, Z.; Zhang, J.; Xiang, B. Synthesis and Enhanced Electrochemical Catalytic Performance of Monolayer $\mathrm{WS}_{2(1-\mathrm{x})} \mathrm{Se}_{2 \mathrm{x}}$ with a Tunable Band Gap. Adv Mater 2015;27:4732-4738.

57. Zou, M.; Zhang, J.; Zhu, H.; Du, M.; Wang, Q.; Zhang, M.; Zhang, X. A 3D Dendritic WSe2 Catalyst Grown on Carbon Nanofiber Mats for Efficient Hydrogen Evolution. J Mater Chem A 2015;3:12149-12153.

58. Wu, R.; Zhang, J.; Shi, Y.; Liu, D.; Zhang, B. Metallic $\mathrm{WO}_{2}-$ Carbon Mesoporous Nanowires as Highly Efficient Electrocatalysts for Hydrogen Evolution Reaction. J Am Chem Soc 2015;137:6983-6986.

59. Fan, X.; Zhou, H.; Guo, X. WC Nanocrystals Grown on Vertically Aligned Carbon Nanotubes: An Efficient and Stable Electrocatalyst for Hydrogen Evolution Reaction. ACS Nano 2015:9:5125-5134.

60. Nayak, A. K.; Verma, M.; Sohn, Y.; Deshpande, P. A.; Pradhan, D. Highly Active Tungsten Oxide Nanoplate Electrocatalyst for Hydrogen Evolution Reaction in Acidic and Near Neutral Electrolytes. ACS Omega 2017;2:7039-7047.

61. Zhu, Y.; Chen, G.; Xu, X.; Yang, G.; Liu, M.; Shao, Z. Enhancing Electrocatalytic Activity for Hydrogen Evolution by Strongly Coupled Molybdenum Nitride@Nitrogen-Doped Carbon Porous Nano-Octahedrons. ACS Catal 2017, 7, 3540-3547.

62. Theerthagiri, J.; Sudha, R.; Premnath, K.; Arunachalam, Prabhakarn; Madhavan, J.; Al-Mayouf, A. M. Growth of Iron Diselenide Nanorods on 
Graphene Oxide Nanosheets as Advanced Electrocatalysts for Hydrogen Evolution Reaction. Int J Hydrogen Energy 2017, 42, 13020-13030.

63. Ren, W.; Zhang, H.; Cheng, C. Ultrafine Pt Nanoparticles Decorated $\mathrm{MoS}_{2}$ Nanosheets with Significantly Improved Hydrogen Evolution Activity. Electrochim Acta 2017;241:316-322.

64. Xu, X. Y.; Dong, X. F.; Bao, Z. J.; Wang, R.; Hu, J. G.; Zeng, H. B. Three Electron Channels Toward two Types of Active Sites in $\mathrm{MoS}_{2} @ \mathrm{Pt}$ Nanosheets for Hydrogen Evolution. Novel Porous Tungsten Carbide Hybrid Nanowires on Carbon Cloth for High-Performance Hydrogen Evolution. J Mater Chem A 2017;5:22654-22661.

65. Ren, B.; Li, D.; Jin, Q.; Cui, H.; Wang, C. Novel Porous Tungsten Carbide Hybrid Nanowires on Carbon Cloth for High-Performance Hydrogen Evolution. J Mater Chem A 2017;5:13196-13203.

66. Kuang, P.; Tong, T.; Fan, K.; Yu, J. In Situ Fabrication of Ni-Mo Bimetal Sulfide Hybrid as an Efficient Electrocatalyst for Hydrogen Evolution over a Wide pH Range. ACS Catal 2017;7:6179-6187.

67. Bhat, K. S.; Barshilia, H. C.; Nagaraja, H. S. Porous Nickel Telluride Nanostructures as Bifunctional Electrocatalyst Towards Hydrogen and Oxygen Evolution Reaction. Int J Hydrogen Energy 2017;42:24645-24655.

68. Min, S.; Qin, J.; Hai, W.; Lei, Y.; Hou, J.; Wang, F. Electrochemical Growth of $\mathrm{MoS}_{\mathrm{x}}$ on $\mathrm{Cu}$ Foam: A Highly Active and Robust ThreeDimensional Cathode for Hydrogen Evolution. Int J Hydrogen Energy 2018;43:4978-4986.

69. Zhang, Y.; Tan, J.; Wen, F.; Zhou, Z.; Zhu, M.; Yin, S.; Wang, H. Platinum Nanoparticles Deposited Nitrogen-Doped Carbon Nanofiber Derived from 
Bacterial Cellulose for Hydrogen Evolution Reaction. Int $\mathrm{J}$ Hydrogen Energy 2018;43:6167-6176.

70. Li, Y.; Niu, S.; Rakov, D.; Wang, Y.; Caban-Acevedo, M.; Zheng, S.; Song, B.; Xu, P. Metal organic framework-derived CoPS/N-doped carbon for efficient electrocatalytic Hydrogen Evolution. Nanoscale 2018;10: 72917297.

71. Yu, S. H.; Chua, D. H. C. Toward High-Performance and Low-Cost Hydrogen Evolution Reaction Electrocatalysts: Nanostructuring Cobalt Phosphide (CoP) Particles on Carbon Fiber Paper. ACS Appl Mater Interfaces 2018;10:14777-14785.

72. Mao, B.; Wang, B.; Yu, F.; Zhang, K.; Zhang, Z.; Hao, J.; Zhong, J.; Liu, Y.; Shi, W. Hierarchical $\mathrm{MoS}_{2}$ Nanoflowers on Carbon Cloth as an Efficient Cathode Electrode for Hydrogen Evolution Under all $\mathrm{pH}$ Values. Int J Hydrogen Energy 2018;43:11038-11046.

73. Zhang, M.; Hu, A.; Liu, Z.; Xu, Y.; Fan, B.; Tang, Q.; Zhang, S.; Deng, W.; Chen, X. Synergistic Effect of Three-Dimensional Cobalt Diselenide/Carbon Nanotube Arrays Composites for Enhanced Hydrogen Evolution Reaction. Electrochim Acta 2018;285:254-261.

74. Sakamoto, R.; Shiotsuki, R.; Wada, K.; Fukui, N.; Maeda, H.; Komeda, J.; Sekine, R.; Harano, K.; Nishihara, H. A Pyrazine-Incorporated Graphdiyne Nanofilm as a Metal-Free Electrocatalyst for the Hydrogen Evolution Reaction. J Mater Chem. A 2018 ;6:22189-22194.

75. Nsabimana, A.; Wu, F.; Lai, J.; Liu, Z.; Luque, R.; Xu, G. Simple Synthesis of Nitrogen-Doped Porous Carbon from Chinese Steamed Bread Flour and 
its Catalytic Application for Hydrogen Evolution Reaction. Electrochim Acta 2018;290:30-37.

76. Zhou, Y.; Yang, Y.; Wang, R.; Wang, X.; Zhang, X.; Qiang, L.; Wang, W.; Wang, Q.; Hu, Z. Rhombic Porous $\mathrm{CoP}_{2}$ Nanowire Arrays Synthesized by Alkaline Etching as Highly Active Hydrogen Evolution Reaction Electrocatalysts. J Mater Chem A 2018;6:19038-19046.

77. Wang, C.; Shi, H.; Liu, H.; Fu, J.; Wei, D.; Zeng, W.; Wan, Q.; Zhang, G.;

Duan, H. Quasi-Atomic-Scale Platinum Anchored on Porous Titanium Nitride Nanorod Arrays for Highly Efficient Hydrogen Evolution. Electrochim Acta 2018;292:727-735.

78. Li, S.; Zhang, L.; Lan, Y.; O'Halloran, K. P.; Ma, H.; Pang, H. Polyoxometalate-Encapsulated Twenty-Nuclear silver-Tetrazole Nanocage Frameworks as Highly Active Electrocatalysts for the Hydrogen Evolution Reaction. Chem Commun 2018;54:1964-1967.

79. Park, J.; Jin, H.; Lee, J.; Oh, A.; Kim, B.; Kim, J. H.; Baik, H.; Joo, S. H.; Lee, K. Highly Crystalline $\mathrm{Pd}_{13} \mathrm{Cu}_{3} \mathrm{~S}_{7}$ Nanoplates Prepared via Partial Cation Exchange of Cu1.81S Templates as an Efficient Electrocatalyst for the Hydrogen Evolution Reaction. Chem Mater 2018;30:6884-6892.

80. Ren, Q.; Jin, H.; Xu, X.; Liu, A.; Li, J.; Wang, J.; Wang, S. Hydrogen Evolution Reaction Catalyzed by Nickel/Nickel Phosphide Nanospheres Synthesized through Electrochemical Methods. Electrochim Acta 2019;298:229-236.

81. Sharma, M. D.; Mahala, C.; Basu, M. AgPd Alloy Nanoparticles Decorated MoS2 2D Nanosheets: Efficient Hydrogen Evolution Catalyst in Wide $\mathrm{pH}$ Condition. ChemistrySelect 2019;4:378-386. 
82. Sun, J.; Ren, M.; Yu, L.; Yang, Z.; Xie, L.; Tian, F.; Yu, Y.; Ren, Z.; Chen,

S.; Zhou, H. Highly Efficient Hydrogen Evolution from a Mesoporous Hybrid of Nickel Phosphide Nanoparticles Anchored on Cobalt Phosphosulfide/Phosphide Nanosheet Arrays. Small 2019;15:1804272.

83. Zheng, L.; Zheng, S.; Wei, H.; Du, L.; Zhu, Z.; Chen, J.; Yang, D. Palladium/Bismuth/Copper Hierarchical Nano-Architectures for Efficient Hydrogen Evolution and Stable Hydrogen Detection. ACS Appl Mater Interfaces 2019;11: 6248-6256.

84. Wei, Y.; He, W.; Sun, P.; Yin, J.; Deng, X.; Xu, X. Synthesis of Hollow $\mathrm{Cu} / \mathrm{Cu}_{2} \mathrm{O} / \mathrm{Cu}_{2} \mathrm{~S}$ Nanotubes for Enhanced Electrocatalytic Hydrogen Evolution. Appl Surf Sci 2019;476:966-971.

85. Hu, Y.; Yu, B.; Li, W.; Ramadoss, M.; Chen, Y. W 2 C Nanodot-Decorated CNT Networks as a Highly Efficient and Stable Electrocatalyst for Hydrogen Evolution in Acidic and Alkaline Media. Nanoscale 2019;11:4876-4884.

86. Nguyen, V.-T.; Nguyen, N.-A.; Ali, Y.; Tran, Q. C.; Choi, H.-S. Graphene Dot Armored PtMo Nanosponge as a Highly Efficient and Stable Electrocatalyst for Hydrogen Evolution Reactions in both Acidic and Alkaline Media. Carbon 2019;146:116-124.

87. Karuppasamy, K.; Jothi, V. R.; Vikraman, D.; Prasanna, K.; Maiyalagan, T.; Sang, B.-I.; Yi, S.-C.; Kim, H.-S. Metal-Organic Framework Derived NiMo Polyhedron as an Efficient Hydrogen Evolution Reaction Electrocatalyst. Appl Surf Sci 2019;478:916-923. 
88. Conway BE, Tilak BV. Behavior and Characterization of Kinetically Involved Chemisorbed Intermediates in Electrocatalysis of Gas Evolution Reactions. Adv Catal 1992;38:1-147.

89. Gileadi E. Electrode Kinetics for Chemists, Chemical Engineers and Material Scientists 1993;164, VCH, Weinheim, Germany.

90. Markovic NM, Grgur BN, Ross PN. Temperature-Dependent Hydrogen Electrochemistry on Platinum Low-Index Single-Crystal Surfaces in Acid Solutions. J Phys Chem B 1997;101:5405-5413.

91. Vielstich W, Lamm A, Gasteiger HA. Handbook of fuel cells: fundamentals, technology, and applications. Hoboken, N.J: Wiley, Chichester, England 2003.

92. Bockris J, Reddy A, Gamboa-Aldeco M. Modern electrochemistry. $2^{\text {nd }}$ ed., New York: Kluwer Academic Publishers; 2002;1480.

93. Macdonald JR. Impedance Spectroscopy, John Wiley and Sons, New York, (Chapter 4) 1987.

94. Badawy WA, Al-Kharafi FM, El-Azab AS. Electrochemical behavior and corrosion inhibition of Al, Al-6061 and Al-Cu in neutral aqueous solutions. Corros Sci 1999;41:709-727.

95. Nady H, Negem M. Ni-Cu nano-crystalline alloys for efficient electrochemical hydrogen production in acid water. RSC Adv 2016;6:51111-51119.

96. Ismail KM, Fathi AM, Badawy WA. Effect of Nickel Content on the Corrosion and Passivation of Copper-Nickel Alloys in Sodium Sulfate Solutions. Corrosion 2004; 60:795-803. 
97. Kucernak ARJ, Naranammalpuram Sundaram VN. Nickel phosphide: the effect of phosphorus content on hydrogen evolution activity and corrosion resistance in acidic medium. J Mater Chem A 2014;2:17435-17445.

98. Badawy WA, Hilal NH, El-Rabiee M, Nady H. Electrochemical behavior of $\mathrm{Mg}$ and some $\mathrm{Mg}$ alloys in aqueous solutions of different $\mathrm{pH}$. Electrochim Acta 2010;55:1880-1887.

99. Badawy WA, Nady H, Negem M. Cathodic Hydrogen Evolution in Acidic Solutions Using Electrodeposited Nano-crystalline Ni-Co Cathodes. Int J Hydrogen Energy 2014; 39:10824-10832.

100. Lavrenko VO. Kinetics of electrochemical anodic oxidation of tungsten. Zhur Fiz Khim 19961;35:1095-1102.

101. Shehata M, Azab S, Fekry AM, Ameer MA. Nano-TiO 2 modified carbon paste sensor for electrochemical nicotine detection using anionic surfactant. Biosens Bioelectron, 2016;79:589-592.

102. Ahmed RA, Fekry AM, Farghali RA. A study of calcium carbonate/multiwalled-carbon nanotubes/chitosan composite coatings on $\mathrm{Ti}-$ 6Al-4V alloy for orthopedic implants. Appl Surf Sci 2013;285B:309-316.

103. Fekry AM. A new simple electrochemical Moxifloxacin Hydrochloride sensor built on carbon paste modified with silver nanoparticles. Biosens Bioelectron, 2017;87:1065-1070.

104. Heakal F, Shehata O, Tantawy N, Fekry AM. Investigation on the corrosion and hydrogen evolution for AZ91D magnesium alloy in single and anioncontaining oxalate solutions. Int J Hydrogen Energy 2012;37:84-94. 
105. Fekry MA, Ghoneim AA, Ameer MA. Electrochemical impedance spectroscopy of chitosan coated magnesium alloys in a synthetic sweat medium. Surf Coat Technol 2014;38:126-132.

106. Abdelrahman, E. M., Abo-Ezz, E. R., Essa, K.. S., El-Araby, T. M., Soliman, K. S. A least-squares variance analysis method for shape and depth estimation from gravity data. J Geophys Eng 2006;3:143-153.

107. Abdelrahman, E. M., Abo-Ezz, E. R., Essa, K. S. Parametric inversion of residual magnetic anomalies due to simple geometric bodies. Exploration Geophys 2012;43,178-189.

108. Essa, K. S., Mehanee, S., Smith, P.A new inversion algorithm for estimating the best fitting parameters of some geometrically simple body from measured self-potential anomalies. Exploration Geophys 2008;39:155-163.

109. Abdelrahman, E. M., Abo-Ezz, E. R., Essa, K. S., El-Araby, T. M., Soliman, K. S. A new least-squares minimization approach to depth and shape determination from magnetic data. Geophys Prospecting 2007;55:433-446.

110. Abdelrahman, E. M., El-Araby, H. M., El-Araby, T. M., Essa, K. S. A leastsquares minimization approach to depth determination from magnetic data. Pure Appl Geophys 2003;160:1259-1271.

111. Badawy WA, Ismail KM, Fathi AM. The influence of the Copper/Nickel Ratio on the Electrochemical Behavior of Cu-Ni Alloys in Acidic Sulfate Solutions. J Alloy Compd 2009;484:365-370. 


\section{Figures captions:}

Fig. 1. (A) SEM micrograph and (B) EDX spectrum corresponding to a freshly polished W electrode. (C) High resolution XPS spectra for W (4f) recorded with W electrode, respectively, before $\left(\mathrm{C}_{1}\right)$ and after contacting a $0.5 \mathrm{M} \mathrm{H}_{2} \mathrm{SO}_{4}$ solution $\left(\mathrm{C}_{2}\right)$.

Fig. 2. XRD patterns for $A$ ) a crude $W$ electrode (without polishing) and B) W electrode treated with $0.5 \mathrm{M} \mathrm{H}_{2} \mathrm{SO}_{4}$ (with polishing).

Fig. 3. (a) Variation of the open circuit potential with time for $\mathrm{W}$ electrode immersed in $\mathrm{H}_{2} \mathrm{SO}_{4}$ solutions of different concentrations at $25{ }^{\circ} \mathrm{C}$. (b) Variation of the open-circuit potential with time for $\mathrm{W}$ and $\mathrm{Pt}$ electrodes in a stable natural aerated $0.5 \mathrm{M} \mathrm{H}_{2} \mathrm{SO}_{4}$ solution.

Fig. 4. (a) Influence of $\mathrm{H}_{2} \mathrm{SO}_{4}$ solution concentration on the catalytic activity of $\mathrm{W}$ electrode at $25{ }^{\circ} \mathrm{C}$. (b) Cathodic polarization curves for HER on $\mathrm{W}$ and $\mathrm{Pt}$ in $0.5 \mathrm{M} \mathrm{H}_{2} \mathrm{SO}_{4}$ at $25^{\circ} \mathrm{C}$.

Fig. 5. Cathodic Tafel lines for HER on $\mathrm{W}$ electrode immersed in aerated $\mathrm{H}_{2} \mathrm{SO}_{4}$ solution of different concentrations at $25{ }^{\circ} \mathrm{C}$.

Fig. 6. Bode plots for $\mathrm{W}$ electrode immersed in $\mathrm{H}_{2} \mathrm{SO}_{4}$ solutions of different concentrations after $60 \mathrm{~min}$ of electrode immersion at $25{ }^{\circ} \mathrm{C}$. (inset): Equivalent circuit model used in the impedance data fitting. Where $R_{\mathrm{s}}=$ solution resistance, $R_{\mathrm{p}}=$ polarization resistance, $C_{\mathrm{dl}}=$ double layer capacitance.

Fig. 7. (a) Bode plots for $\mathrm{W}$ electrode at $\mathrm{E}=-750 \mathrm{mV}$ vs $\mathrm{SCE}$, for HER at different concentrations of $\mathrm{H}_{2} \mathrm{SO}_{4}$ solutions at $25{ }^{\circ} \mathrm{C}$. (b) Nyquist plots for $\mathrm{W}$ electrode at $\mathrm{E}=-750 \mathrm{mV}$ vs $\mathrm{SCE}$, for HER at different concentrations of $\mathrm{H}_{2} \mathrm{SO}_{4}$ solutions at $25^{\circ} \mathrm{C}$.

Fig. 8. (a) Bode plots of $\mathrm{W}$ after $1 \mathrm{~h}$ of electrode immersion in stagnant naturally aerated $0.5 \mathrm{M} \mathrm{H}_{2} \mathrm{SO}_{4}$ solution at $-750 \mathrm{mV}$ and $25{ }^{\circ} \mathrm{C}$. (b) Nyquist plots for $\mathrm{W}$ after $1 \mathrm{~h}$ of electrode immersion in stagnant naturally aerated $0.5 \mathrm{M} \mathrm{H}_{2} \mathrm{SO}_{4}$ solution at $750 \mathrm{mV}$ and $25^{\circ} \mathrm{C}$. 

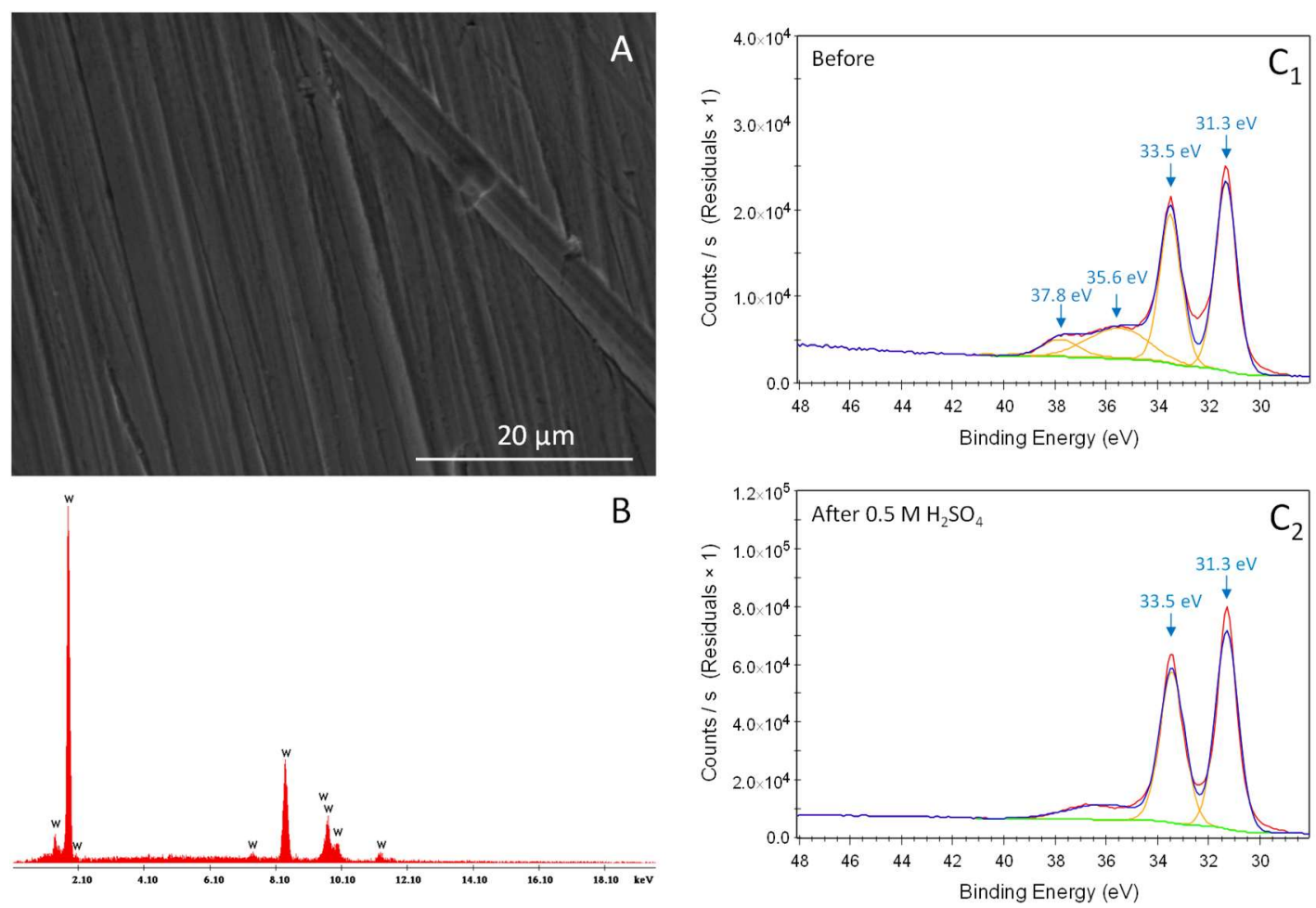

Fig. 1. 


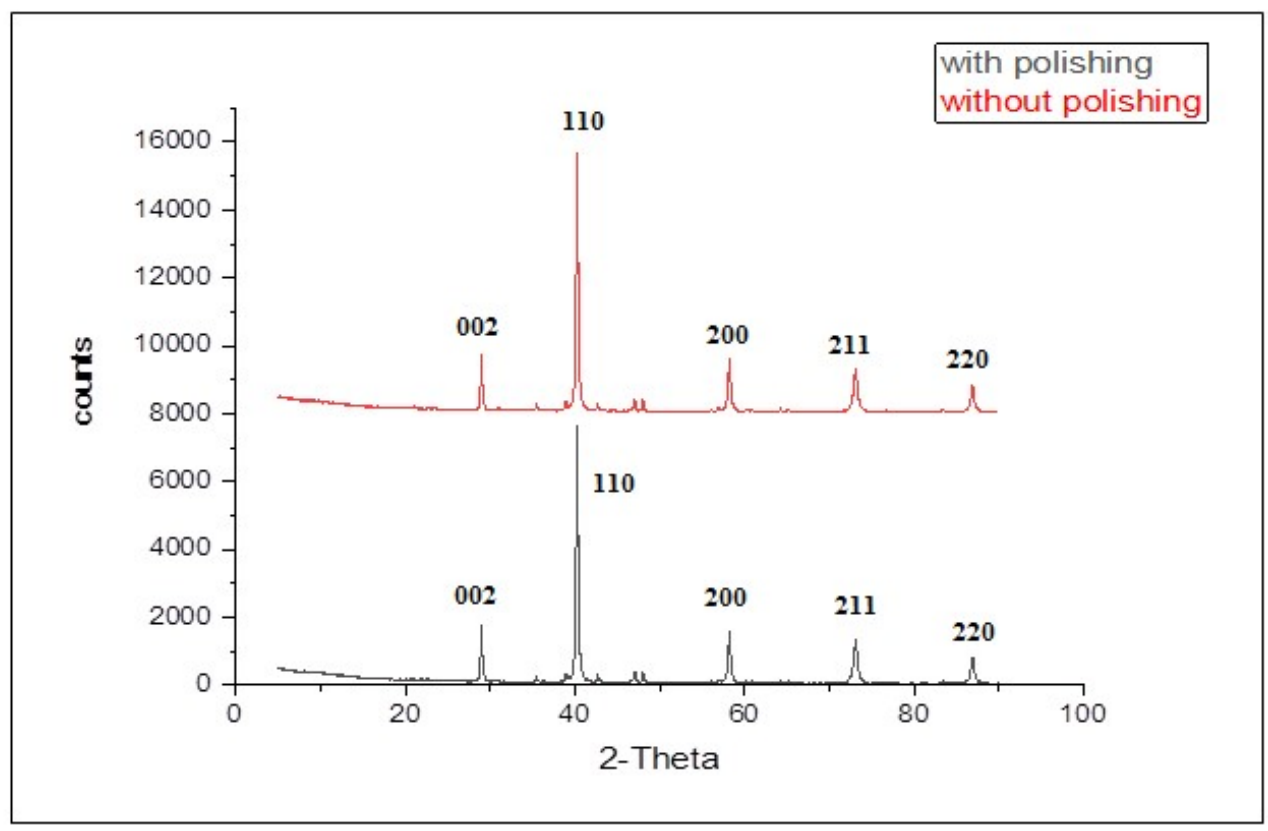

Fig. 2. 

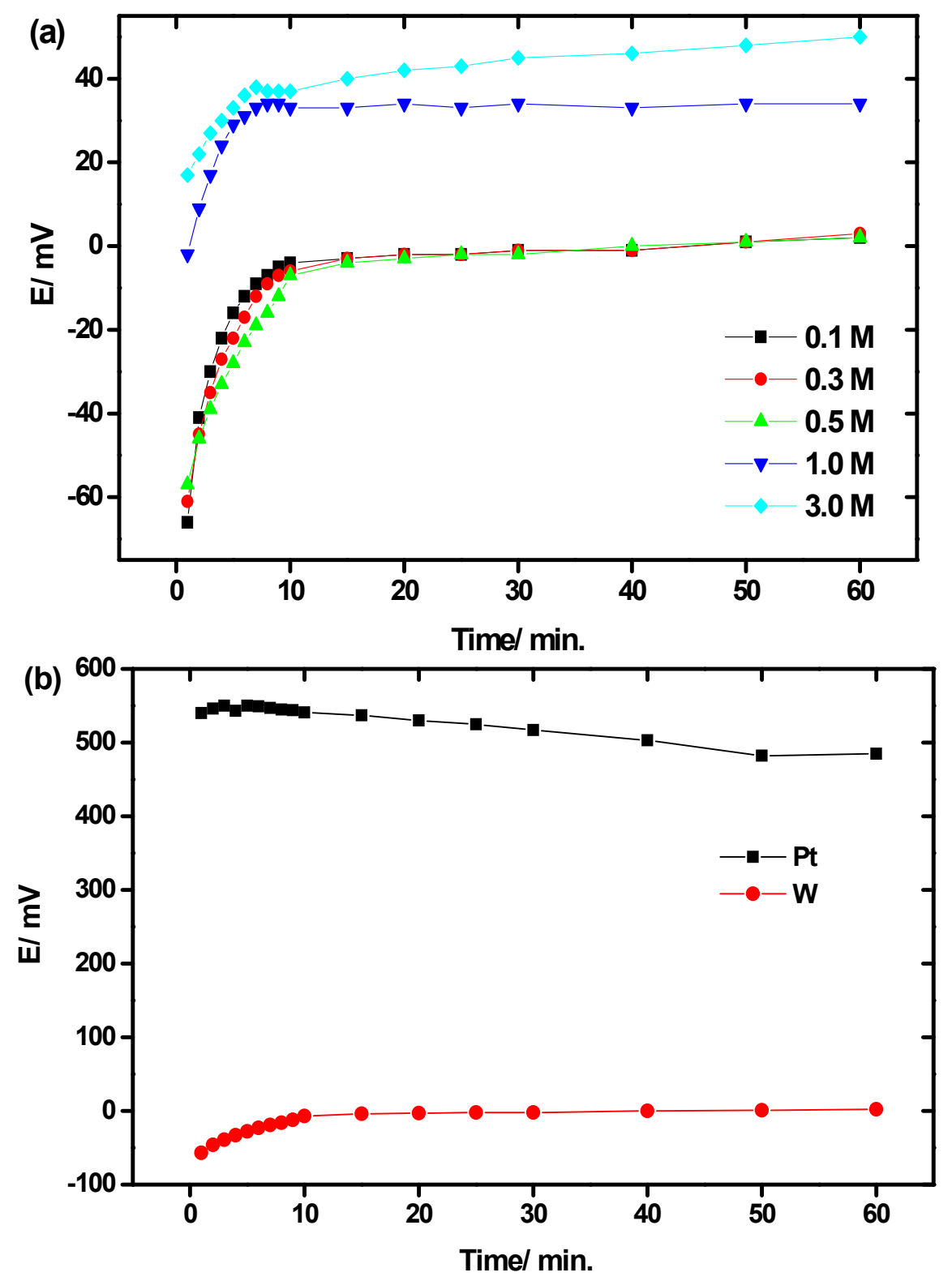

Fig. 3 

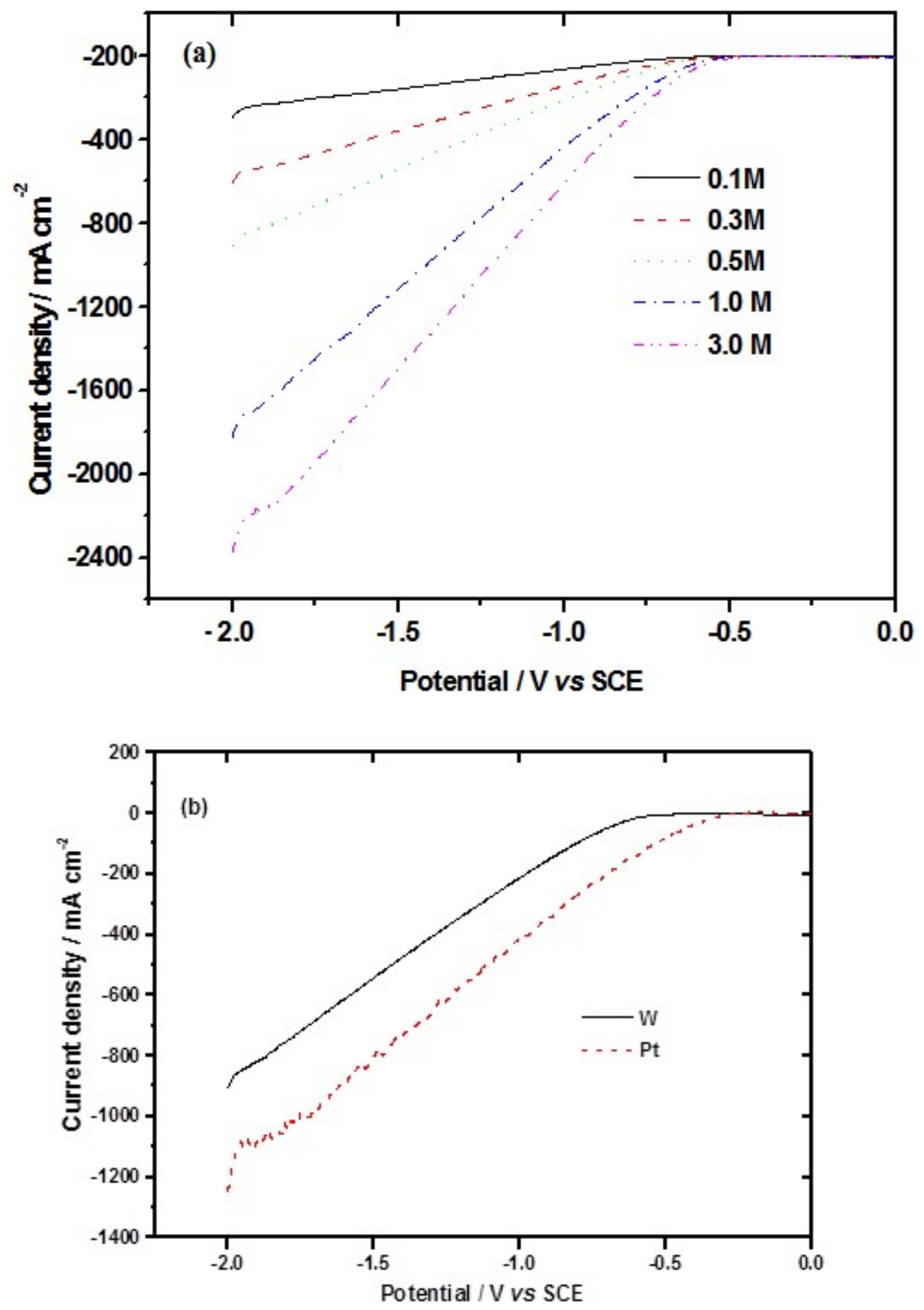

Fig. 4 


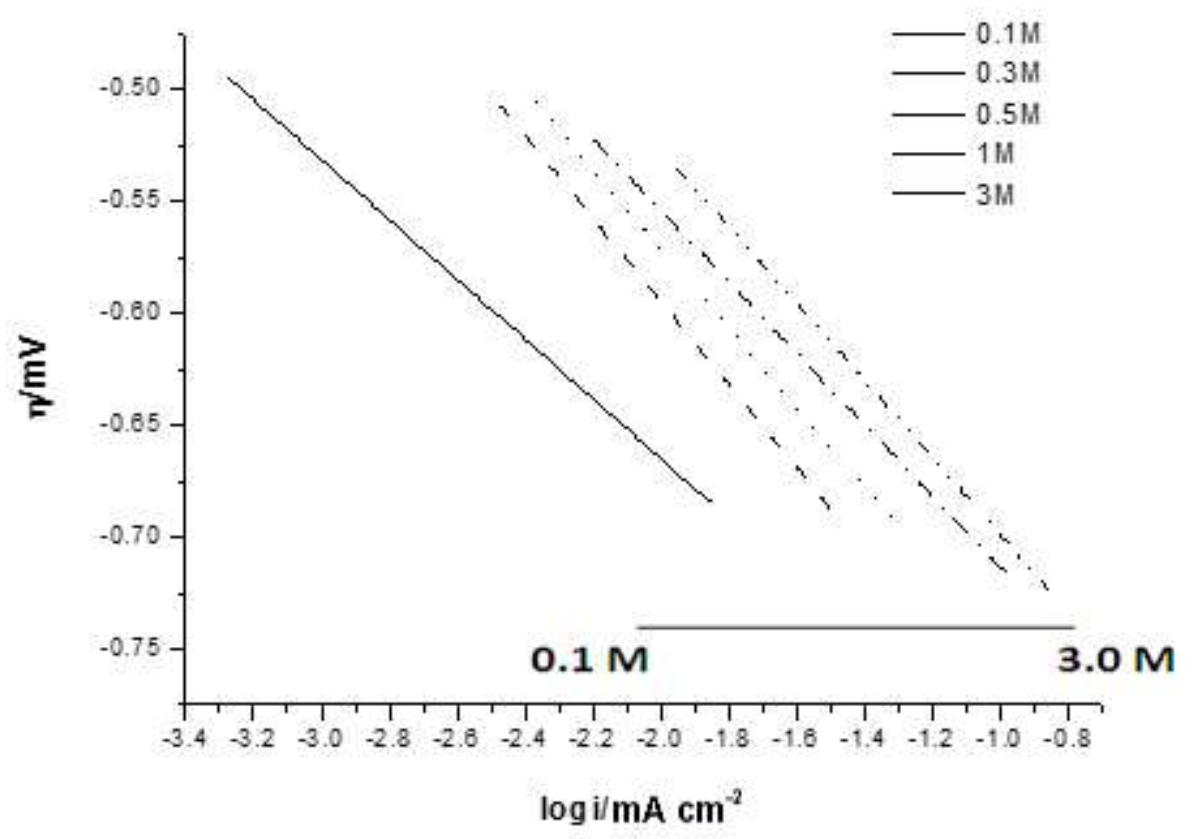

Fig. 5 


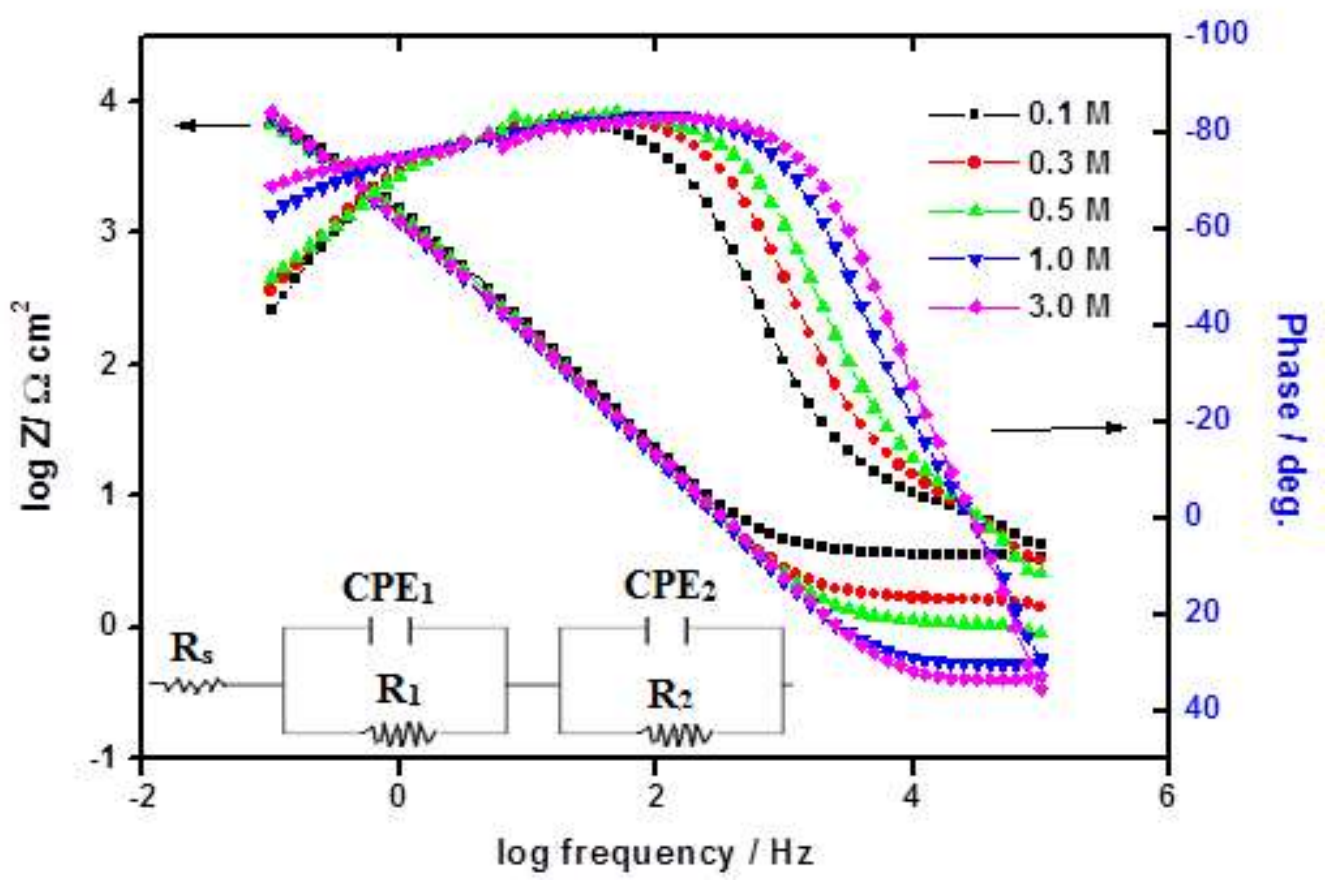

Fig. 6 

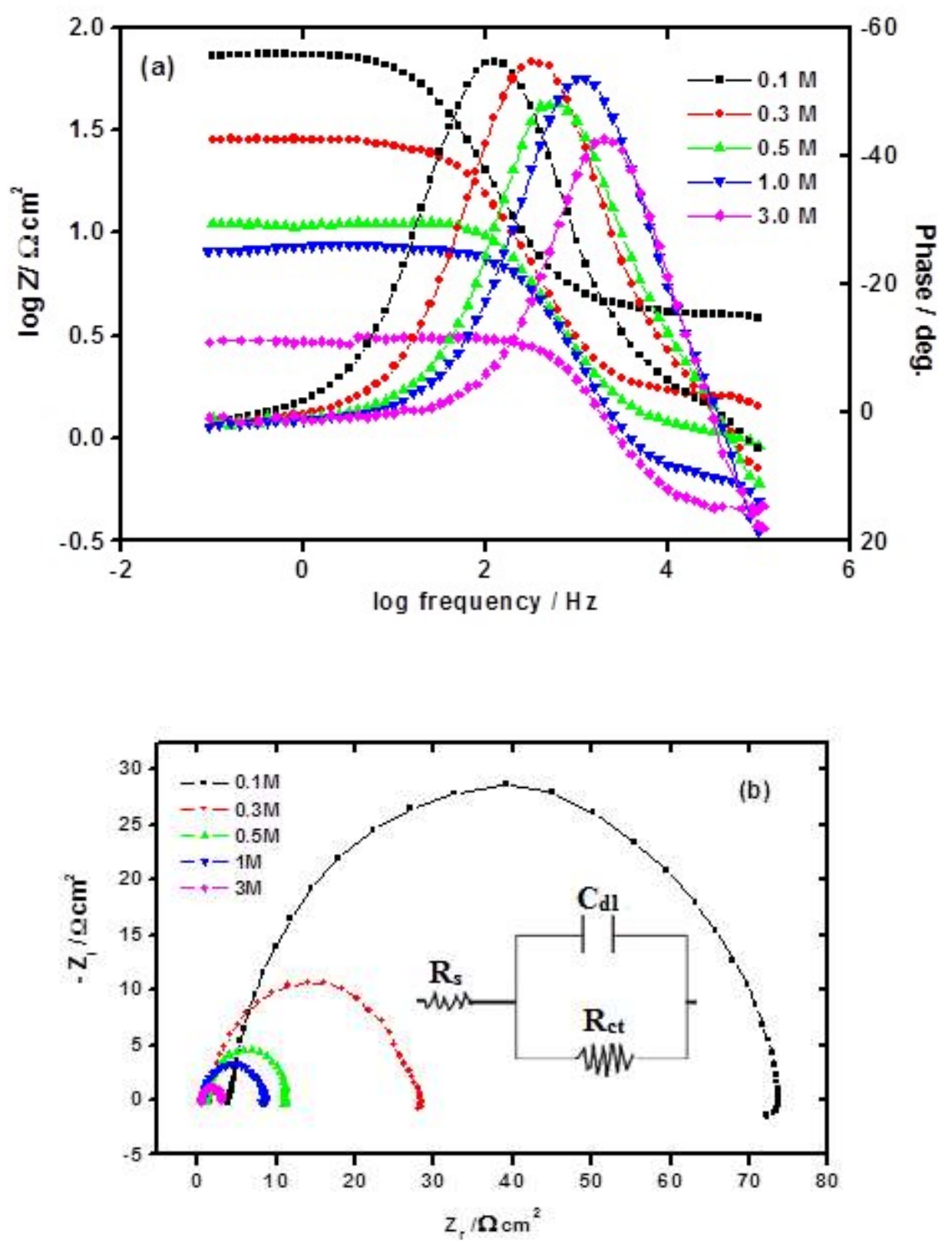

Fig. 7 

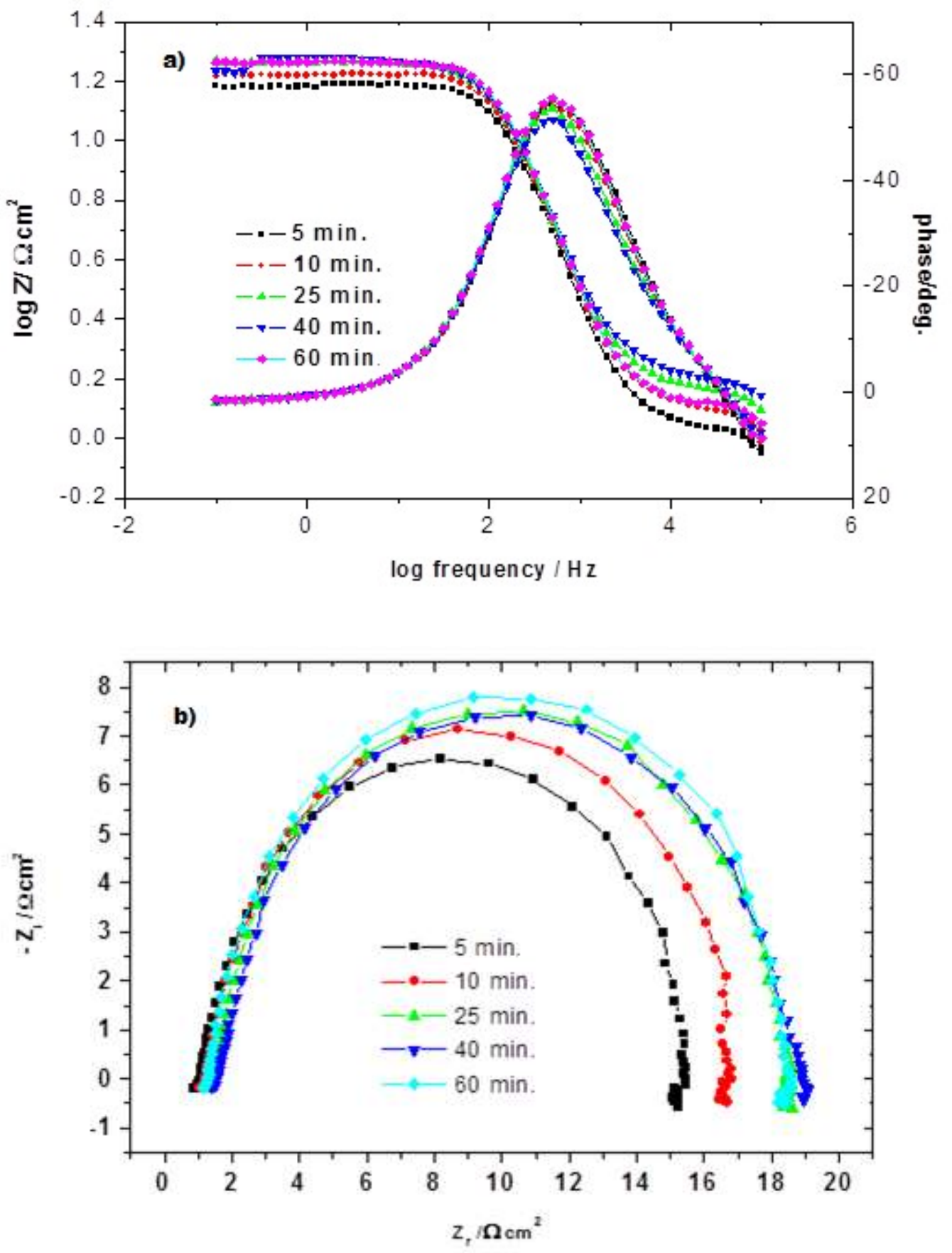

Fig. 8 


\section{Tables}

Table 1- Comparative performance of various HER electrocatalysts in acidic media $\left(0.5 \mathrm{M} \mathrm{H}_{2} \mathrm{SO}_{4}\right)$.

\begin{tabular}{|c|c|c|c|}
\hline Electrode material & $\begin{array}{l}\text { Tafel slope } \\
\left(\mathrm{mV} \text { dec }^{-1}\right)\end{array}$ & $\begin{array}{c}\text { Overpotential } \\
\left(\text { at } 10 \mathrm{~mA} / \mathrm{cm}^{2}\right) \\
(\mathbf{m V})\end{array}$ & Reference \\
\hline Core-shell $\mathrm{MoO}_{3}-\mathrm{MoS}_{2}$ nanowires & $50-60$ & 254 & {$[50]$} \\
\hline $\mathrm{MoS}_{2}$ nanoparticles on $\mathrm{Au}$ electrode & 69 & 226 & {$[51]$} \\
\hline Defect-rich $\mathrm{MoS}_{2}$ nanosheets & 50 & 190 & {$[52]$} \\
\hline Nanostructured $\mathrm{Ni}_{2} \mathrm{P}$ & 46 & 117 & {$[53]$} \\
\hline $\mathrm{CoS}_{2}$ & 42.4 & 231 & {$[54]$} \\
\hline $\mathrm{CoP}$ nanocystals on $\mathrm{C}$ nanotubes & 54 & 122 & {$[55]$} \\
\hline $\mathrm{WSe}_{2}$ film on glassy carbon electrode & 100 & 150 & {$[56]$} \\
\hline Dendritic $\mathrm{WSe}_{2}$ on carbon nanofiber & 80 & 228 & {$[57]$} \\
\hline $\mathrm{WO}_{2}$-carbon mesoporous nanowires & 44 & 56 & {$[58]$} \\
\hline WC nanocystals on $\mathrm{C}$ nanotubes & 72 & 145 & {$[59]$} \\
\hline $\begin{array}{l}\mathrm{WO}_{3} \text { (precipitated on glassy carbon) } \\
\mathrm{WO}_{3} \text { (annealed on glassy carbon) } \\
\mathrm{Pt} / \text { carbon }\end{array}$ & $\begin{array}{c}43.9 \\
39.5 \\
29\end{array}$ & $\begin{array}{l}147 \\
73 \\
24\end{array}$ & {$[60]$} \\
\hline MoN on N-doped C nano-octahedrons & 54 & 62 & [61] \\
\hline $\begin{array}{l}\mathrm{FeSe}_{2} \text { nanorods on graphene oxide } \\
\text { nanosheets }\end{array}$ & 64 & 250 & {$[62]$} \\
\hline Pt nanoparticles on $\mathrm{MoS}_{2}$ nanosheets & $\begin{array}{l}52 \\
70\end{array}$ & $\begin{array}{l}31 \\
36\end{array}$ & $\begin{array}{l}{[63]} \\
{[64]}\end{array}$ \\
\hline WC hybrid nanowires on carbon cloth & 55 & 118 & {$[65]$} \\
\hline $\mathrm{NiS}_{2} / \mathrm{MoS}_{2}$ on glassy carbon electrode & $58-83$ & $204-284$ & {$[66]$} \\
\hline $\mathrm{NiTe} / \mathrm{NiTe}_{2}$ nanosheets on carbon rod & 87.4 & 422 & [67] \\
\hline $\mathrm{MoS}_{\mathrm{x}}$ electrodeposited on $\mathrm{Cu}$ foam & 43.6 & 200 & {$[68]$} \\
\hline $\begin{array}{l}\text { Pt nanoparticles on } \mathrm{N} \text {-doped carbon } \\
\text { nanofiber }\end{array}$ & 35 & 47 & [69] \\
\hline CoPS nanoparticles on N-doped carbon & 68 & 80 & {$[70]$} \\
\hline Nanostructured CoP on C fiber paper & 49.7 & 128 & [71] \\
\hline $\mathrm{MoS}_{2}$ nanoflowers on carbon cloth & 50 & 94 & {$[72]$} \\
\hline $\mathrm{CoSe}_{2}$ on carbon nanotube arrays & 36.7 & 204 & {$[73]$} \\
\hline Pyrazine-incorporated graphdiyne film & 75 & 475 & {$[74]$} \\
\hline $\mathrm{N}$-doped porous carbon & 77 & 220 & {$[75]$} \\
\hline $\mathrm{CoP}_{2}$ nanowire arrays on carbon cloth & 67 & 56 & {$[76]$} \\
\hline
\end{tabular}




\begin{tabular}{|c|c|c|c|}
\hline Pt on porous TiN nanorod array & 38.6 & 39.7 & {$[77]$} \\
\hline $\begin{array}{l}\text { Polyoxometalate-encapsulated Ag- } \\
\text { tetrazole nanocage frameworks }\end{array}$ & 82 & 234 & {$[78]$} \\
\hline $\mathrm{Pd}_{13} \mathrm{Cu}_{3} \mathrm{~S}_{7}$ Nanoplates & 49.6 & 64 & [79] \\
\hline $\mathrm{Ni}-\mathrm{Ni}_{\mathrm{X}} \mathrm{P}$ nanospheres on carbon cloth & 76 & 164 & {$[80]$} \\
\hline AgPd alloy decorated $\mathrm{MoS}_{2}$ nanosheets & $82-109$ & $215-229$ & [81] \\
\hline Mesoporous $\mathrm{CoS}|\mathrm{Ni}| \mathrm{P}$ nanosheet array & 45.2 & 41 & {$[82]$} \\
\hline $\mathrm{Pd} / \mathrm{Bi} / \mathrm{Cu}$ nano-architectures & 61 & 79 & {$[83]$} \\
\hline Hollow $\mathrm{Cu} / \mathrm{Cu}_{2} \mathrm{O} / \mathrm{Cu}_{2} \mathrm{~S}$ nanotubes & 107 & 86 & [84] \\
\hline $\mathrm{W}_{2} \mathrm{C}$ nanodots on $\mathrm{C}$ nanotube networks & 57.4 & 176 & {$[85]$} \\
\hline $\begin{array}{l}\text { PtMo nanosponge wrapped with } \\
\text { graphene dots }\end{array}$ & 32 & 32 & {$[86]$} \\
\hline $\mathrm{NiMo} / \mathrm{NiMoO}_{4}$ polyhedron on $\mathrm{Ni}$ foam & 98.9 & 80 & [87] \\
\hline W electrode & 25.0 & 320 & This work \\
\hline
\end{tabular}


Table 2- Tafel parameters for the HER on $\mathrm{W}$ electrode in $\mathrm{H}_{2} \mathrm{SO}_{4}$ solution with different concentrations at $25{ }^{\circ} \mathrm{C}$.

\begin{tabular}{cccccc}
\hline $\begin{array}{c}\mathbf{C o n c} \\
/ \mathbf{M}\end{array}$ & $\begin{array}{c}\boldsymbol{i}_{\mathbf{0}} \\
/ \mathbf{m A ~ c m}^{-2}\end{array}$ & $\begin{array}{c}-\boldsymbol{b} \\
/ \mathbf{m V d e c}^{-1}\end{array}$ & ${ }_{\mathrm{c}} \boldsymbol{\alpha}$ & $\mathbf{1 - \boldsymbol { \alpha } _ { \mathbf { c } }}$ & $\begin{array}{c}\text { Onset pot. } \\
/ \mathbf{V}\end{array}$ \\
\hline 0.1 & 0.1168 & 0.02677 & 0.1668 & 0.8332 & -0.5965 \\
0.3 & 0.1182 & 0.02535 & 0.1202 & 0.8798 & $0.5874-$ \\
0.5 & 0.1185 & 0.02552 & 0.1258 & 0.8742 & $0.5828-$ \\
1 & 0.1337 & 0.02592 & 0.1395 & 0.8605 & -0.5783 \\
5 & 0.1345 & 0.02563 & 0.1296 & 0.8704 & -0.5691 \\
\hline
\end{tabular}

Table 3- Equivalent circuit parameters for $\mathrm{W}$ electrode measured after $1 \mathrm{~h}$ of electrode immersion in $\mathrm{H}_{2} \mathrm{SO}_{4}$ solution with different concentrations at $25{ }^{\circ} \mathrm{C}$.

\begin{tabular}{cccc}
\hline $\begin{array}{c}\text { Conc. } \\
/ \mathbf{M}\end{array}$ & $\begin{array}{c}\boldsymbol{R}_{\mathbf{s}} \\
\boldsymbol{\Omega} \mathbf{~ c m}^{\mathbf{2}}\end{array}$ & $\begin{array}{c}\boldsymbol{R}_{\mathbf{T}} \\
/ \mathbf{k} \boldsymbol{\Omega} \mathbf{~ c m}^{\mathbf{2}}\end{array}$ & $\begin{array}{c}\boldsymbol{C}_{\mathbf{T}} \\
/ \boldsymbol{\mu} \mathbf{F} \mathbf{~ c m}^{\mathbf{2}}\end{array}$ \\
\hline 0.1 & 5.94 & 22.27 & 129.6 \\
0.3 & 7.37 & 22.84 & 123.9 \\
0.5 & 12.00 & 24.71 & 108.1 \\
1.0 & 6.19 & 42.31 & 49.24 \\
3.0 & 3.59 & 69.63 & 26.68 \\
\hline
\end{tabular}

Table 4- Equivalent circuit parameters for $\mathrm{W}$ recorded after $1 \mathrm{~h}$ of electrode immersion in $\mathrm{H}_{2} \mathrm{SO}_{4}$ solution of different concentration under $-750 \mathrm{mV}$ cathodic polarizations at $25{ }^{\circ} \mathrm{C}$.

\begin{tabular}{cccc}
\hline $\begin{array}{c}\text { Conc. } \\
/ \mathbf{M}\end{array}$ & $\begin{array}{c}\boldsymbol{R}_{\mathbf{s}} \\
\boldsymbol{/ \Omega} \mathbf{~ c m}^{\mathbf{2}}\end{array}$ & $\begin{array}{c}\boldsymbol{R}_{\mathbf{c t}} \\
/ \boldsymbol{\Omega} \mathbf{~ c m}^{2}\end{array}$ & $\begin{array}{c}\boldsymbol{C}_{\mathbf{d l}} \\
/ \boldsymbol{\mu} \mathbf{F} \mathbf{c m}^{\mathbf{2}}\end{array}$ \\
\hline 0.1 & 4.03 & 69.33 & 91.81 \\
0.3 & 1.51 & 26.61 & 75.34 \\
0.5 & 1.19 & 9.88 & 80.53 \\
1.0 & 0.625 & 7.84 & 64.18 \\
3.0 & 0.465 & 2.66 & 75.40 \\
\hline
\end{tabular}

Table 5- Equivalent circuit parameters for $\mathrm{W}$ electrode measured after different intervals of electrode immersion in $0.5 \mathrm{M} \mathrm{H}_{2} \mathrm{SO}_{4}$ solution under $-750 \mathrm{mV}$ at $25{ }^{\circ} \mathrm{C}$.

\begin{tabular}{|c|c|c|c|}
\hline $\begin{array}{l}\text { Time } \\
/ \text { min }\end{array}$ & $\begin{array}{c}R_{\mathrm{s}} \\
/ \Omega \mathrm{cm}^{2}\end{array}$ & $\begin{array}{c}\boldsymbol{R}_{\mathrm{ct}} \\
/ \boldsymbol{\Omega} \mathbf{c m}^{2}\end{array}$ & $\begin{array}{c}C_{\mathrm{dl}} \\
/ \mu \mathrm{F} \mathbf{~ m}^{2}\end{array}$ \\
\hline 5 & 1.15 & 14.19 & 70.88 \\
\hline 10 & 1.31 & 15.37 & 65.44 \\
\hline 25 & 1.48 & 16.96 & 75.05 \\
\hline 40 & 1.58 & 17.26 & 73.75 \\
\hline 60 & 1.45 & 13.84 & 72.68 \\
\hline
\end{tabular}

